\title{
Modelling radioactivity dispersion in the Alborán Sea, western Mediterranean
}

\author{
R. Periáñez \\ Department of Applied Physics 1, EUITA, Universidad de Sevilla, Ctra Utrera km 1, \\ 41013-Sevilla, Spain
}

\begin{abstract}
A numerical model which simulates the dispersion of non-conservative radionuclides in the Alboran Sea has been developed. Water currents are obtained from two hydrodynamic models working on the same domain: a 2D depth-averaged model is used two calculate tides and a 2-layer has been applied to obtain the residual (mean) circulation. The output of the hydrodynamic models is first applied to calculate suspended particle concentrations and sedimentation rates over the domain, which are also required by the radionuclide transport model. This assumes that radionuclides may be present in three phases: dissolved, suspended matter and bed sediments. Exchanges between the liquid and solid phases are described through kinetic transfer coefficients. The model has been applied to simulate the dispersion of 137-Cs and 239,240$\mathrm{Pu}$ introduced in the sea from atmospheric fallout. Measured and computed radionuclide concentrations in the water column and in bed sediments are, in general, in good agreement.
\end{abstract}

\section{INTRODUCTION}

The Alborán Sea is the only connection between the Atlantic Ocean and the Mediterranean Sea and has a high ecological and economic interest. Moreover, it is one of the most productive areas of the whole Mediterranean Sea. Thus, a considerable effort has been made in the last years to study sedimentation processes in the Alborán Sea, radionuclide distributions in waters and sediments, and metal and radionuclide fluxes through the Strait of Gibraltar since they affect the biogeochemistry of the entire Mediterranean Sea. These processes are studied by means of numerical modelling, for the first time, in the present work. The water circulation is studied by means of two models: a depth-averaged model is used to calculate tides and a two-layer model is applied to obtain the geostrophic (mean) flow. Computed currents are used to calculate sediment transport and sedimentation rates over the area. Then, results of the hydrodynamic and sediment transport models are used to simulate the dispersion of ${ }^{137} \mathrm{Cs}$ and ${ }^{239,240} \mathrm{Pu}$. A mathematical description of the interactions of dissolved radionuclides with the solid phases (suspended matter and bed sediments) in a two-layered sea has been developed. Uptake/release reactions have been described by means of kinetic transfer coefficients. Computed concentrations of radionuclides in the water column and in the bed sediments have been compared with measurements in the Alborán Sea. Both set of data are, in general, in good agreement. In particular, the model predicts very different distributions in the bed sediment depending on the geochemical behaviour of the radionuclide. The computed partition of plutonium between water and suspended sediments is also correctly calculated by the model. Radionuclide inventories in the Alborán Sea and fluxes through the Strait of Gibraltar have been calculated and compared with previous experimental estimates. Finally, some numerical experiments have been carried out to determine flushing-times of the system. This is the first time that such a complete study of radionuclide dynamics in the Alborán Sea has been carried out.

\section{MODEL DESCRIPTION}

Currents at any given time and position, which are required to solve the advection terms of the dispersion equation for suspended sediments and radionuclides, are obtained through the addition of 
the instantaneous tidal current plus the residual flow. Indeed, tides are relevant for the transport of substances in the area close to the Strait of Gibraltar, where associated currents are stronger. Inside the Alborán Sea, where weaker tidal currents exist, residual circulation is dominant.

Tidal and residual currents are obtained from two hydrodynamic models working on the same domain: a 2D depth-averaged model [1] is used for calculating tides and a two-layer model [2] is applied to obtain the residual flow. These are reasonable approaches, as discussed earlier [2]. The hydrodynamic models are run in advance and results are stored in files that will be later used by the dispersion models (suspended sediments and radionuclides).

The transport of sediments is described by an advection-diffusion equation for each water layer to which some terms are added. These are external sources of particles, terms describing particle deposition on the seabed and erosion from the bed to the water column, vertical settling and diffusive transport through the interface separating the two water layers. The formulation of these processes is based upon standard formulae. Thus, the erodability constant is used for the erosion term. Particle settling and deposition are described using the settling velocity, which is obtained from Stoke's law. Critical erosion and deposition stresses are used as usually. Details on the mathematical formulation may be seen elsewhere $[1,2]$. Finally, it is also possible to calculate net sedimentation rates (SR) as the balance between the deposition and erosion terms.

Non conservative radionuclides are those which do not remain dissolved in the water column, but have a certain affinity to be fixed to particles. If the radionuclide is introduced in the surface water layer, it will be fixed to settling suspended particles and their deposition on the sea bed will contaminate the bottom sediment. Of course there also are advection/diffusion processes in both water layers, diffusion of dissolved radionuclides and of particles through the pycnocline and direct adsorption of pollutants on the seabed. The exchanges between the dissolved and solid phases may be described in terms of kinetic transfer coefficients. Thus, assuming that adsorption/release reactions are governed by a single reversible reaction, a coefficient $\mathrm{k}_{1}$ governs the transfer from the liquid to the solid phase and a coefficient $\mathrm{k}_{2}$ governs the inverse process. Also, the migration of radionuclides to the deep sediment must be included since simulations over several years are carried out. Thus, radionuclides deposited on the sediment surface will be buried by particle deposition and will migrate below the mixed sediment layer that directly interacts with the dissolved phase. This effect may be easily treated as a decay process [2].

All the equations are solved applying explicit finite difference schemes on a 2 minute resolution grid for both longitude and latitude and with appropriate boundary conditions [2]. Second order accuracy schemes are used for advection and diffusion terms.

\section{RESULTS}

A detailed comparison of results of the tidal model with measurements in the Alborán Sea is given in [3]. The calculated residual flows for the upper and lower layers, for the mean water exchanges through the Strait of Gibraltar, are presented in Fig. 1. In the upper layer, the jet of Atlantic Water entering through the Strait of Gibraltar flows towards the east along the Spanish coast and partially curves to the south at about $-3.5^{\circ}$ longitude. An anticyclonic gyre known as WAG (Western Alborán Gyre) is formed. This is an almost permanent feature of circulation in the surface layer of the Alborán Sea, although some episodes of gyre migration and even disappearance have been described. The vertical scale of the gyre is about $200 \mathrm{~m}$. A westward circulation is obtained for the bottom layer, mainly along the southern coast of the sea. More dense Mediterranean Water flows towards the Atlantic Ocean below the lighter Atlantic Water that enters the Mediterranean Sea. The inflow of Atlantic Water is larger than the Mediterranean Water outflow to compensate the excess of evaporation over precipitation and river supply in the Mediterranean.

Computed sedimentation rates are, except in the river plumes, of the order of $10^{-2} \mathrm{~g} / \mathrm{cm}^{2}$ year. The smallest SR is obtained in some areas of the Strait of Gibraltar and the Alborán Sea, where larger currents are present in the lower layer and/or stronger tidal currents exist. These values are in agreement with 
measured SR in the area [9]. Computed particle concentrations in the upper layer are about $0.4 \mathrm{~g} / \mathrm{m}^{3}$ in the Strait of Gibraltar and in the Atlantic jet in the Alborán Sea. Concentration decreases in the WAG and in the south part of the sea to some $0.2 \mathrm{~g} / \mathrm{m}^{3}$. Slightly higher concentrations, about $0.4-0.5 \mathrm{~g} / \mathrm{m}^{3}$, are obtained in most of the bottom layer. These values are in agreement with [4].

The model has been applied to ${ }^{137} \mathrm{Cs}$ and ${ }^{239,240} \mathrm{Pu}$. Computed concentrations of these radionuclides in the water column and in bed sediments have been compared with measurements in the sea. Radionuclide inventories in the water column and in bed sediments have been calculated as well and compared with previous estimations. Generally speaking, computed magnitudes are in agreement with experimental measurements or estimates. All these results may be seen in detail in [2].
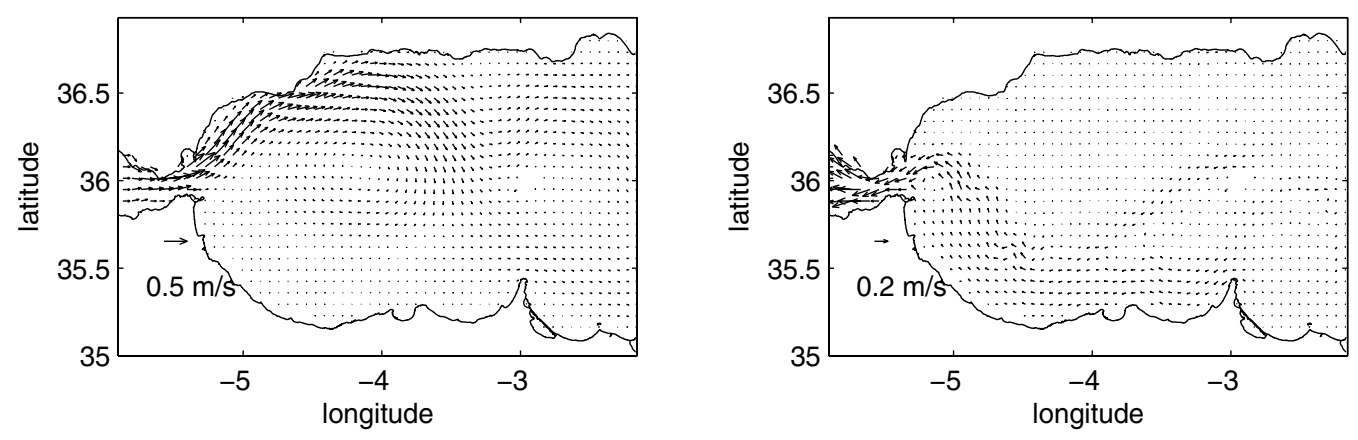

Figure 1. Computed mean currents in the upper (left) and lower (right) water layers.
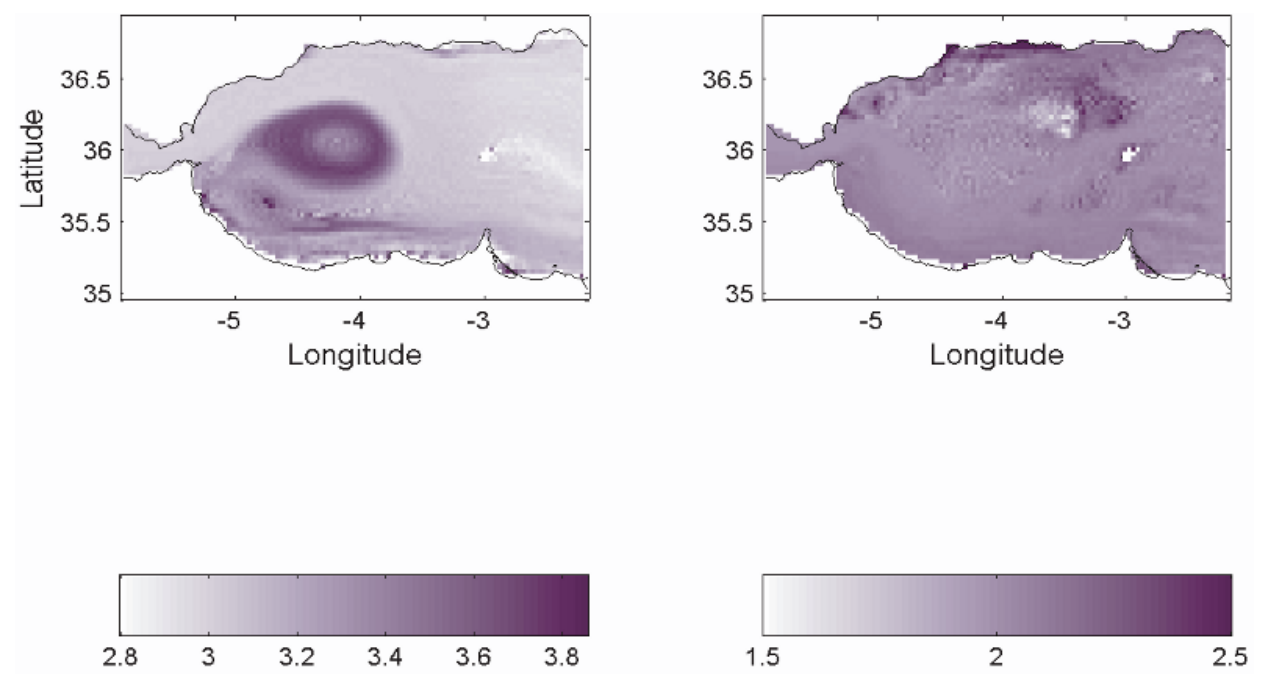

Figure 2. Computed ${ }^{137} \mathrm{Cs}$ concentrations in unfiltered water $\left(\mathrm{Bq} / \mathrm{m}^{3}\right)$ in the upper and lower water layers (left and right respectively) of the Alboran Sea.

As an example, the computed distributions of ${ }^{137} \mathrm{Cs}$ in unfiltered water in the upper and lower water layers are shown in Fig. 2. The distributions in the upper layer are similar for both $\mathrm{Cs}$ and $\mathrm{Pu}$, showing higher concentrations in the area occupied by the WAG. This is due to the fact that some water is trapped in the gyre and thus its radionuclide concentration increases as a result of the atmospheric input. Nevertheless, simulations are made under a steady residual flow condition, thus this pattern may be destroyed by episodes of migration and disappearance of the WAG and winds. However, it is worth 
commenting that the pattern of higher radionuclide concentrations (for ${ }^{210} \mathrm{~Pb}$, introduced by atmospheric deposition as well) in the centre of the oceanic gyres (in both the Pacific and North Atlantic) has already been detected [5]. Consequently, the radionuclide enhancement in the WAG is a real process, although overestimated because of the simulation conditions (steady residual flow). The distribution of $\mathrm{Pu}$ in bed sediment is show in Fig. 3, which is rather different to that of Cs (not shown) due to the different geochemical behaviour of both radionuclides.

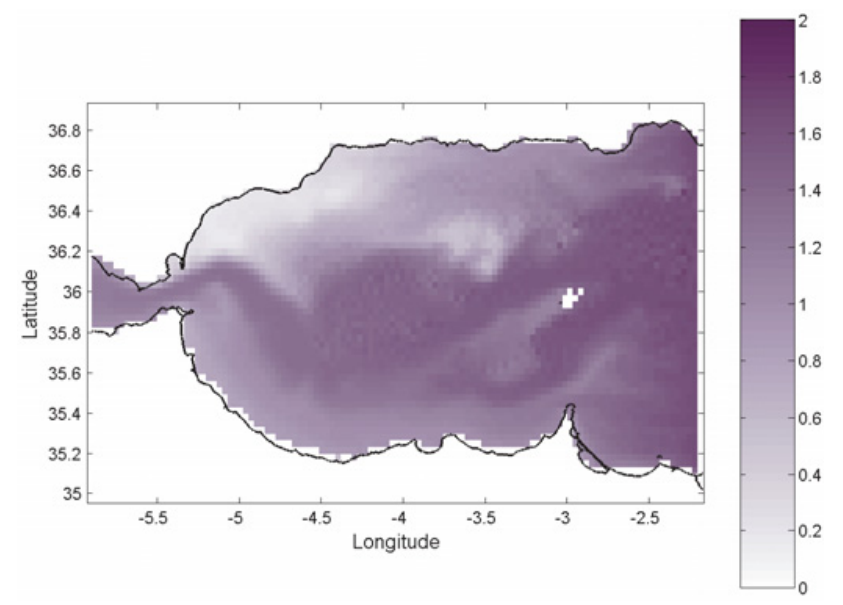

Figure 3. Computed distribution of ${ }^{239,240} \mathrm{Pu}(\mathrm{Bq} / \mathrm{kg})$ in bed sediments.

A correct estimation of ${ }^{137} \mathrm{Cs}$ levels in bed sediments and in the water column is made. Also, the model reproduces the observed fact that essentially the same Cs concentrations exist in both water layers. Although the model slightly underestimates Pu concentrations in the water column, it is obtained that concentrations in the deep water layer are essentially a factor 2 higher than in the surface layer because of the efficient removal of dissolved plutonium by settling suspended particles [2]. The partition of plutonium between water and suspended matter is correctly given by the model: less than $5 \%$ of plutonium is fixed to suspended particles. This small value is due to the low suspended matter concentrations existing in this environment. Radionuclide partition between water and suspended matter is found to be at equilibrium over all the sea except in the upper water layer in the Strait of Gibraltar. This is probably due to the strong currents in this area.

The fluxes of the two studied radionuclides through the Strait of Gibraltar (through a north-south section at the longitude of Tarifa, in the centre of the Strait) have been finally evaluated from the model results. In spite of the variability of the water exchanges used in the different estimations that have been made, all results are in reasonable agreement and differences reach a factor 2 as maximum, although it seems that the model tends to overestimate the inflow of Cs into the Mediterranean. Results are summarized in Table 1.

The turn-over-time in a given domain is defined as the time in which a tracer inventory in the water column decreases by a factor $e$ in the region. This is a relevant parameter for water quality of a given system, and has been determined for both radionuclides of interest. The model is started from the computed distribution of each radionuclide in water, suspended matter and sediment, and the system evolves without any external source of radionuclides. Tides are not used in the calculations, but only the residual flow. Radionuclide inventories within the Alborán Sea are evaluated in the region comprised between $-4,5^{\circ}$ and $-2,7^{\circ}$ longitude for each time step. Thus, the system-wide flushing time (it is the same as the turn-over-time in the case of constant flow) has actually been determined [8]. Following the method in [8], flushing times have been determined for each water layer separately and for both the dissolved and suspended matter phases. Results are given in Table 2. It may be seen that flushing time 
for $\mathrm{Pu}$ is about one order of magnitude larger than that of Cs. This is due to the higher affinity of Pu to be fixed to the solid phase, which makes it less mobile in the aquatic environment. Essentially the same values are obtained for water and for suspended matter.

In the case of constant flow through a region, the flushing time may be determined as $V / q$, where $V$ is the region volume and $q$ is the flow magnitude. If this relation is applied to the surface layer a flushing time of 80 days would be obtained, which is shorter than those in Table 2. This is due to the fact that the WAG traps water, and thus radionuclides remain in the gyre. This also explains why the flushing times are shorter for the bottom than for the surface water layer. Moreover, we are including radionuclide interactions with the solid phases, which make them less mobile. Of course, this effect is more evident in the case of $\mathrm{Pu}$. The effects of water-sediment interactions in flushing times had not been investigated before.

Table 1. Annual fluxes of radionuclides $(\mathrm{TBq})$ in inflow Atlantic and outflow Mediterranean waters. Water exchanges used in calculations are given in $\mathrm{Sv}\left(1 \mathrm{~Sv}=10^{6} \mathrm{~m}^{3} / \mathrm{s}\right)$. The source of data is included.

\begin{tabular}{|c|c|c|c|c|c|}
\hline \multicolumn{2}{|c|}{$137-\mathrm{Cs}$} & \multicolumn{2}{|c|}{$239,240-\mathrm{Pu}$} & \multirow{2}{*}{ inflow/outflow } & \multirow{2}{*}{ source } \\
\hline $\mathrm{F}_{\text {in }}$ & $\mathrm{F}_{\text {out }}$ & $\mathrm{F}_{\text {in }}$ & $\mathrm{F}_{\text {out }}$ & & \\
\hline 118 & 75 & 0.27 & 0.44 & $1.25 / 1.20$ & model \\
\hline $72 \pm 18$ & $60 \pm 13$ & $0.28 \pm 0.11$ & $0.62 \pm 0.16$ & $0.90 / 0.90$ & {$[6]$} \\
\hline & & 0.22 & 0.87 & $1.39 / 1.32$ & {$[4]$} \\
\hline 64 & 51 & 0.25 & 0.53 & $0.81 / 0.76$ & {$[7]$} \\
\hline
\end{tabular}

Table 2. Flushing times (days) in the surface and bottom water layers and for water and suspended matter.

\begin{tabular}{|c|c|c|c|c|}
\hline & \multicolumn{2}{|c|}{$137-\mathrm{Cs}$} & \multicolumn{2}{c|}{$239,240-\mathrm{Pu}$} \\
\cline { 2 - 5 } & surface & bottom & surface & bottom \\
\hline \multicolumn{5}{|c|}{ Water } \\
\hline Flushing time & 292 & 121 & 3720 & 814 \\
\hline \multicolumn{5}{|c|}{ Suspended matter } \\
\hline Flushing time & 248 & 123 & 4422 & 893 \\
\hline
\end{tabular}

\section{CONCLUSIONS}

The dynamics of ${ }^{137} \mathrm{Cs}$ and ${ }^{239,240} \mathrm{Pu}$ in the Alborán Sea has been studied by means of numerical modelling. The model consists of three sub-models describing hydrodynamics, sediment transport and radionuclide dispersion. The Alborán Sea has been treated as a two-layered system, and an appropriate description of radionuclide transport in it has been developed. Uptake/release radionuclide reactions between the liquid and solid phases are described by means of kinetic transfer coefficients.

Computed and measured radionuclide concentrations in the water column and in bed sediments have been compared. Different behaviours are observed for $\mathrm{Cs}$ and $\mathrm{Pu}$ due to their different geochemistry. Generally speaking, the model produces results in agreement with measurements. A correct estimation of ${ }^{137} \mathrm{Cs}$ levels in bed sediments and in the water column is made. Also, the model reproduces the observed fact that essentially the same Cs concentrations exist in both water layers. Although the model slightly underestimates $\mathrm{Pu}$ concentrations in the water column, it is obtained that concentrations in the deep water layer are essentially a factor 2 higher than in the surface layer because of the efficient removal of dissolved plutonium by settling suspended particles.

An interesting effect has been observed. It consists of an enhancement of radionuclide concentrations in the WAG. This effect has also been observed in the centre of oceanic gyres in the Atlantic and Pacific. It is due to the fact that water remains trapped in the gyre region, remaining relatively isolated from the surroundings, and thus accumulating radionuclides introduced from the atmosphere. This pattern may 
be broken by fluctuations of the mean flow, as episodes of disappearance of the WAG, and by winds. Consequently, the accumulation effect, although real, is overestimated by the model.

Radionuclide fluxes through the Strait of Gibraltar have been finally evaluated. They are in relative good agreement with previous estimations based upon radionuclide concentration measurements in the Strait. Finally, flushing times of the region have been calculated through some numerical experiments. They are larger for the upper than for the lower water layer due to the presence of the WAG.

\section{Acknowledgments}

Work supported by the Research Project of Excellence RNM-419, Junta de Andalucía, Spain. The author is indebted to the Spanish Ministerio de Educación y Ciencia for a fellowship to stay during three months in the University of Wales, where part of this work was carried out.

\section{References}

[1] Periáñez, R. Modelling the Dispersion of Radionuclides in the Marine Environment. SpringerVerlag, Heidelberg, 2005.

[2] Periáñez, R. J Environ Radioact 99 (2008), 694-715.

[3] Periáñez, R. J Environ Radioact 90 (2006), 48-67.

[4] León-Vintró, L., Mitchell, P.I., Condren, O.M., Downes, A.B., Papucci, C. and Delfanti, R. Sci Tot Environ 237/238 (1999), 77-91.

[5] Ivanovich, M. and Harmon, R.S. Uranium-series Disequilibrium: Applications to Earth, Marine and Environmental Sciences. Clarendon Press, Oxford, 1992.

[6] Gascó, C., Antón, M.P., Delfanti, R., González, A.M., Meral, J., and Pappuci, C. J Environ Radioact 62 (2002), 241-262.

[7] Gómez, F. Mar Poll Bull 46 (2003), 685-694.

[8] Choi, K.W. and Lee, J.H.W. J Mar Syst 50 (2004), 263-281.

[9] Masqué, P., Fabres, J., Canals, M., Sanchez-Cabeza, J.A., Sanchez-Vidal, A., Cacho, I., Calafat, A.M., and Bruach, J.M. Mar Geol 193 (2003), 207-233. 